\title{
O DESENVOLVIMENTO MORAL NA PERSPECTIVA DE PIAGET, KOHLBERG E GILLIGAN
}

\author{
Rafaela de Cássia Mendes Chaves ${ }^{1}$ \\ Yara Rodrigues de la Iglesia²
}

\section{RESUMO}

O presente trabalho foi realizado por meio de uma revisão bibliográfica, tendo como objetivo compreender o desenvolvimento da moral a partir da perspectiva cognitivo-desenvolvimental. Esta perspectiva entende o desenvolvimento moral associado aos componentes cognitivos. Dentro dessa abordagem, encontramos dois autores que exerceram grande influência na pesquisa sobre o desenvolvimento da moral: Jean Piaget (1896-1980) e Lawrence Kohlberg (19271987). No entanto, a teoria de Kohlberg tem sido questionada por Carol Gilligan (1936-atualmente), precursora das discussões sobre as diferenças de gênero no campo da psicologia moral. Apesar de não ter elaborado uma teoria com níveis de desenvolvimento moral, a pesquisadora desenvolveu o conceito de ética do cuidado. Gilligan sugere que a teoria de Kohlberg não é adequada para avaliar as mulheres. Pode-se concluir que é fundamental para o campo da pedagogia a discussão sobre o desenvolvimento da moral, dentro da abordagem estudada, porque esses conhecimentos contribuem para a intervenção na prática pedagógica e para o aprimoramento da formação docente.

Palavras-chave: Desenvolvimento Moral. O juízo Moral. A Ética do Cuidado.

\section{ABSTRACT}

This study was conducted through a literature review, aiming to understand the development of morality from the cognitive-developmental perspective. This perspective understands the moral development associated with cognitive components. Within this approach we find two authors who exerted great

${ }^{7}$ Acadêmica da Faculdade Unina. Licenciada em Pedagogia. E-mail: r.mendes1526@gmail.com 2 Professora da Faculdade Unina. Doutora e mestre em Educação na linha de Psicologia da Educação. E-mail: yara@unina.edu.br 
influence on research on the development of morality: Jean Piaget (1896-1980) and Lawrence Kohlberg (1927-1987). However, Kohlberg's theory has been questioned by Carol Gilligan (1936-currently), precursor of discussions on gender differences in the field of moral psychology. Despite not having developed a theory with levels of moral development, the researcher developed the concept of ethics of care. Gilligan suggests that Kohlberg's theory is not suitable for evaluating women. It can be concluded that it is fundamental for the field of pedagogy to discuss the development of morality, within the approach studied, because this knowledge contributes to intervention in pedagogical practice and to the improvement of teacher training.

Keywords: Moral Development. Moral judgment. The Ethics of Care.

\section{INTRODUÇÃO}

Não é de hoje que regras estão presentes em nossa sociedade, especialmente as regras morais, que são entendidas a partir de diferentes perspectivas como leis invisíveis. São essas mesmas regras que servem de modelo de como devemos nos comportar na sociedade em que estamos inseridos. Essas regras não estão escritas em um manual, no entanto a literatura aponta que é por meio da socialização que a criança aprende e interioriza as regras básicas da sociedade, bem como os modelos comportamentais do grupo ao qual pertence. Mas, como internalizamos essas regras morais? Com que idade aprendemos o que é certo ou errado? Diante do exposto, esta pesquisa se propôs a responder à seguinte pergunta: É possível desenvolver a moral?

Este trabalho ocorreu por meio de uma pesquisa bibliográfica seletiva e conta com contribuições de grandes autores: Jean Piaget (1896-1980) e Lawrence Kohlberg (1927-1987), que compreendem a moral com um caráter universalista, em que o foco se direciona para a dimensão racional, fazendo associação da moral a princípios e valores de igualdade, reciprocidade e justiça. Também se abordou as contribuições de Carol Gilligan (1936 - atualmente) e o conceito da ética do cuidado.

Jean Piaget deixou uma contribuição muito significativa para a psicologia moral, apesar de não ser esse o foco de seus estudos. $O$ autor distingue dois 
tipos de orientação moral: a heterônoma, radicada na obediência, no constrangimento e no respeito unilateral, e a autônoma, centrada na cooperação e no respeito mútuo. A teoria de Lawrence, influenciada por Piaget, exibe a moral dividida por estágios evolutivos e sequenciais, divididos em três níveis e seis estágios de desenvolvimento moral que perpassam o espaço de heteronomia e autonomia.

Contrapondo alguns argumentos de Kohlberg, surge uma nova ótica da moral, oferecida por Carol Gilligan, que se opõe às concepções de inferioridade moral atribuídas às mulheres por Piaget e Kohlberg.

\section{O DESENVOLVIMENTO MORAL A PARTIR DE PIAGET, KOHLBERG E GILLI- GAN}

Apesar de a discussão sobre a moral ter feito parte do processo educativo como prática, o estudo sistemático do desenvolvimento moral só teve início com Jean Piaget, por meio da publicação do seu livro - Le jugement moral chez l'enfant -, publicado em 1932 (DELVAL; ENESCO, 1994), que foi traduzido ao português como O julgamento moral da criança, tornando-se um clássico na área da psicologia moral.

Piaget dedicou a maior parte de sua vida a explicar como os seres humanos aprendem. Além de construir uma teoria do conhecimento, ele aspirava estabelecer uma teoria sobre a moral. Da mesma forma que tentou aclarar como funcionam as estruturas mentais e como essas estruturas são construídas nas trocas incessantes entre o organismo e o meio, ele criou uma teoria sobre o desenvolvimento da moral (RAMOZZI-CHIAROTTINO, 1997). O autor procurava explicar como, a partir do mundo amoral do bebê, é possível ao ser humano constituir uma consciência moral autônoma (FREITAS, 1999).

Apesar de não ter se aprofundado em suas pesquisas, Piaget é considerado o precursor do estudo da moralidade, que é definida por ele "como um sistema de regras, e a essência de toda moralidade deve ser procurada no respeito que o indivíduo adquire por essas regras" (1994, p. 23). Dito de outra forma, "a dimensão moral do desenvolvimento psicológico refere-se ao respeito, por parte do indivíduo, pelas regras sociais e ao desenvolvimento do sentido de justiça 
no sentido da reciprocidade e da igualdade" (COIMBRA, 1990, p. 31).

Ao contrário de Durkheim, que defendia que a essência da Educação Moral era ensinar às crianças a obediência às regras morais da sociedade e ao bem da mesma, Piaget, em seu estudo, "procurou entender como as crianças desenvolvem o respeito pelas regras e qual a concepção de Reciprocidade e Igualdade entre os indivíduos e com a sociedade, e mais ainda, como se constroem esses conceitos de regras e de respeito mútuo" (QUEIROZ; LIMA, 2010, p. 110).

Nesse sentido, o autor encontra no jogo de regras um campo propício para estudar a questão de como é possível a aquisição de uma consciência autônoma. As regras do jogo, como as regras morais "se transmite de geração em geração e se mantêm unicamente graças ao respeito que os indivíduos têm por elas" (PIAGET, 1992, p. 2). Sendo assim, busca compreender o juízo moral a partir da perspectiva da criança, descrevendo as regras morais que ocorrem enquanto elas jogam.

Piaget salienta a importância da constituição das regras para o desenvolvimento moral na criança, afirmando que a moral se organiza em um sistema de regras. As pesquisas de Piaget (1994) possibilitaram determinar estágios do desenvolvimento moral. A seguir, serão descritos os três estágios, nomeadamente: anomia, heteronomia e autonomia moral.

a) Anomia: A criança tem atitudes conectadas às necessidades básicas e, em sua maioria, há ligação moral, regras ou leis e, quando obedece a regras exteriores, é por ligação à prática habitual e não pela consciência moral de certo e errado.

b) Heteronomia: Para a criança, seguir o certo é executar as regras, que são imutáveis, logo, o julgamento de errado é absoluto e não serão aceitas quaisquer outras interpretações, justificativas ou esclarecimentos.

c) Autonomia: É a última fase do desenvolvimento moral, em que o indivíduo reflete sobre as regras e suas construções por meio da cooperação. Só então, surge a possibilidade de gerar novas regras por meio da determinação grupal.

Nesta abordagem, as questões da moralidade apontam para o conceito de 
estágio e a noção de que existe uma sequência constante de reorganizações, relacionadas com a idade, que se traduzem na construção progressiva, qualitativamente diferenciada e ativa do sujeito como sujeito moral (COIMBRA, 1990). No entanto, de acordo com Piaget (1994), o desenvolvimento moral não está totalmente vinculado à idade cronológica. Nesse sentido, pode-se considerar que, nos adultos, a heteronomia convive com a autonomia se as formas de eles se relacionarem com os outros tiverem características heterônomas.

O trabalho de Piaget sobre a moralidade das crianças não se estendeu além das regras dos jogos e dos dilemas morais, "os dilemas morais apresentam situações de vida real onde se dá a oportunidade de escolha, seguido de um inquérito (entrevista) que busca levantar as razões das escolhas feitas" (QUEIROZ; LIMA, 2010, p. 123). Sua aspiração consistia em observar como ocorre a adaptação progressiva do sujeito às regras e à consciência que possui delas, à medida que amadurece cronológica e cognitivamente.

Lawrence Kohlberg (1927-1987), psicólogo norte-americano, é quem dá continuidade às pesquisas de Jean Piaget. A teoria kohlberiana se afasta do conteúdo da moral e busca se aproximar de como ela se desenvolve nas pessoas. Não há relevância na ideia do que é o certo ou o errado, mas sim como tomamos noção de certo e errado, o que, a priori, aumenta à medida que as crianças crescem. Kolberg estende suas pesquisas para crianças maiores, em torno dos 16 anos.

A teoria kohlberiana é uma busca da definição científica e filosófica da moralidade, onde qualquer descrição da forma ou modelo de estrutura social é necessariamente dependente de estruturas cognitivas, assim como os afetos e as atitudes dos indivíduos também não podem ser distinguidos dessa estrutura. Os motivos de uma ação moral têm também um elemento cognitivo formal. (LIMA, 2004, p. 15).

Assim como sua teoria, Kohlberg (1992) "deixa claro que seus estágios são etapas de raciocínio de justiça, centrados em aspectos de retidão e não de emoções ou ações. O que os aproxima à teoria piagetiana, já que passa pelo espaço heteronomia-autonomia, e traz certo distanciamento já que ele conceitua esses estágios de forma mais precisa" (KADOOKA; LEPRE; EVANGELISTA, 2015, p. 
1610). Kohlberg, ao estudar os adolescentes, percebeu que esses conceitos são insuficientes para compreender todos os tipos de raciocínio moral.

De acordo com Fini (1991), Kolberg, ao estudar o desenvolvimento moral e definir estágios, realizou pesquisas com crianças e jovens de diferentes nacionalidades, crenças, de zona rural e urbana, utilizando um método de entrevistas inspirado em Piaget. Ele apresentava dilemas morais, por sua vez hipotéticos, para serem analisados e julgados um por vez, de forma que os sujeitos pudessem justificar suas respostas. A autora ainda exemplifica:

Kohlberg apresentava aos sujeitos da pesquisa uma sequência de histórias ou dilemas morais hipotéticos destinados a colocar o indivíduo diante de um conflito entre a conformidade habitual a regras ou à autoridade em oposição a uma resposta utilitária ou de bem maior. Os dilemas apresentam conflitos entre padrões simultaneamente aceitos por grande parte da comunidade. (FINI,1991, p. 62).

Conforme Silva (2003), Piaget estudou a vida moral até o início da adolescência, enquanto Kohlberg foi além, compreendendo até o nível pleno da maturidade e da moral. São três níveis divididos em seis estágios: Nível I - Pré-convencional, Nível II - Convencional e Nível III - Pós-convencional. Cada um desses níveis está dividido em dois estágios.

Nível I - Pré-convencional: esse nível "engloba a maior parte das crianças até os nove anos de idade, alguns adolescentes e grande número de delinquentes adolescentes e adultos." (COIMBRA, 1990, p. 33). Neste nível, não há um código moral pessoal, pois se segue o que é dado por adultos e/ou mais velhos, ou o que se considera autoridade, e o julgamento de certo ou errado remete às consequências físicas. Em outras palavras, este nível pode ser considerado como a moralidade da punição e da obediência; as consequências físicas determinam o que está certo.

I. Estágio I - Orientação para o castigo e a obediência: De acordo com Fini (1990, p. 63), "o padrão se concentra em prêmio ou castigo, o foco está em situações externas e físicas, que é delegado pela autoridade, pois o único ponto de vista relevante aqui é o da autoridade"; não há questionamentos, pois tende-se a não 
aborrecer o superior.

II. Estágio II - Individualismo ou hedonismo: Para Coimbra (1990, p. 34), "o raciocínio moral aqui pode ser definido como falsamente egoísta, poderá haver possibilidades de pensar no outro desde que haja reciprocidade ou garantias". Essa reciprocidade ainda é de certa forma egoísta e mercantilista.

Nível II - Convencional. Segundo Lima (2004, p. 16), este "é o nível em que se localiza a maioria dos adolescentes e adultos de nossa sociedade e de outras. O termo convencional designa conformidade e manutenção das regras sociais, é baseado na autoridade. Há expectativas ou acordos da sociedade". Neste nível, o indivíduo identifica-se com as regras e expectativas dos outros, principalmente das autoridades. "A orientação moral de correto liga-se a práticas e regras sociais já determinadas pelo que se considera autoridade, que podem ser instituições ou pessoas reconhecidas socialmente" (BATAGLIA; MORAIS; LEPRE, 2010, p. 26).

III. Estágio III - Moral de bom menino ou boa menina: Este é o estágio do bom menino, pois o sujeito que se encontra nele preocupa-se em fazer o que se espera dele, em ser bom para os que importam para ele, como pais, professores e chefes. O que importa é manter boas relações com os outros.

IV. Estágio IV - Orientação para lei e ordem. Para Vale (2014), o quarto estágio é regulado pelas convenções sociais, como os costumes e normas que são estabelecidos e aceitos em sociedade.

Nível III - Pós-convencional, autônomo ou nível de princípios. Este é o último nível do desenvolvimento da moral e, para Macedo (2015, p. 44), neste estágio, "o valor moral reside na conformidade do eu com modelos, direitos e deveres compartilhados ou compartilháveis". Compreendem-se valores e princípios que sejam válidos para todos e desligados de autoridades de que pessoas ou grupos possam exercer.

V. Estágio $\vee$ - Orientação para o contrato social. O sujeito não 
obedece às leis por se tratar de leis, há contestações às leis e aos costumes tradicionais, que podem causar situações de injustiças, logo deverão sofrer mudanças (MACEDO, 2015).

VI. Estágio VI - Princípios universais de consciência. Há uma minoria de pessoas que alcança este estágio, pois a orientação moral implica o respeito a si mesmo e ao outro e isso leva em conta, principalmente, o respeito pelos pontos de vista e interesses do outro. Busca-se princípios universais como a igualdade, a dignidade dos seres humanos, justiça, entre outros (LIMA, 2004).

O estágio do raciocínio moral que certo indivíduo alcançou é determinado por juízes que avaliam as respostas pessoais e hipotéticas - dilemas morais -, histórias em que o indivíduo é posto diante de uma escolha moral. Essas histórias são de natureza filosófica e envolvem questões de responsabilidade, de motivos ou intenções. O estágio de um indivíduo não é determinado pela natureza da escolha que ele faz diante do referido dilema, mas antes com base nas razões que são apresentadas para essa escolha (VALENTE, 2002).

Como Piaget, Kohlberg não só entende que a progressão através desses estágios é sequencial e invariante, mas também que não são muitas as pessoas que alcançam os estágios mais elevados. O autor afirmou que só 10\% dos americanos adultos raciocinam ao nível pós-convencional (VALENTE, 2002).

Por outro lado, Carol Gilligan (1936), filósofa e psicóloga feminista, que trabalhou com Kolberg, anos depois, questiona a metodologia utilizada por ele. Na concepção da pesquisadora, as mulheres partem de uma estrutura de raciocínio moral que prioriza o cuidado e o bem-estar do outro. A teoria gilliginiana se opõe às concepções de inferioridade moral atribuídas às mulheres por Piaget e Kohlberg. Ao se contrapor à teoria kohlberiana, Gilligan (1982), assim como outros seguidores de Kohlberg, também fizeram uso do mesmo dilema clássico utilizado por Kohlberg.

Baseando-se nos resultados obtidos em seus estudos, a pesquisadora desenvolveu o conceito da ética do cuidado, contribuindo significativamente para discussões no que diz respeito às diferenças no desenvolvimento moral de homens e mulheres, evidenciando as duas orientações éticas que permeiam a 
existência e o processo de socialização humana.

A ideia embrionária da diferença de percepção da realidade entre homens e mulheres é explorada por Gilligan em seu livro In a different voice: Psychological Theory and Women's development, publicado em 1982, em que descreve duas formas do pensar ético. Essas duas formas são apresentadas e identificadas cultural e contextualmente como masculinas e femininas, e são ilustradas como o "corte umbilical com a mãe", que, para os homens, é uma necessidade para o processo de individuação e autonomia; já, para as mulheres, não existe a necessidade de separação, ocorre o inverso, e há problemas no processo de individuação. E assim nasce o princípio do norteamento ético, o ideal que as mulheres têm de si mesmas como cuidadoras. (TOLDY, 2015 p. 586). Essas duas vozes são permeadas por orientações diferentes, uma pela ética do cuidado e outra pela ética da justiça, e se expressam com elementos característicos de cada uma dessas vozes, apresentados no Quadro 1:

Quadro 1 - Diferentes orientações entre homens e mulheres

\begin{tabular}{|l|l|}
\hline \multicolumn{1}{|c|}{ A VOZ DOS HOMENS } & \multicolumn{1}{c|}{ A VOZ DAS MULHERES } \\
\hline Teoria & Modelo \\
Justiça/Gratificação & Racional - Emocional \\
Autonomia Individual & Impacto nas relações - Eu-em-relação \\
Independência & Compaixão - Responsabilidade \\
Regras/Estritas & Preocupação e cuidado - Abstração \\
Direitos Individuais & Contextualização - Focalização no futuro \\
Conflitos de direitos & Criação de expectativas \\
Certo/Errado & Várias "tonalidades" \\
Aqui e agora & Interdependência \\
Rapidez & Redes laterais relacionais \\
Menos centrado no cuidado & Orientação para as pessoas \\
Hierarquia/ comando & Evitação da dor \\
Receio de intimidade & Receio de falta de intimidade \\
\hline
\end{tabular}

Fonte: Gilligan (1984 apud Marinho, 2004, p. 76)

Gilligan identifica a voz diferente pertencente às mulheres como a voz do cuidado e se opõe à voz da justiça existente nos homens. Seus estudos sugerem que o caminho do desenvolvimento moral e a evolução do conceito 
de moralidade são os mesmos para as mulheres, pois, desde muito cedo, em suas vidas, acreditam que o cuidado com os outros seja o mais importante. Nas relações com o outro, procura-se arrumar as coisas para que o outro não seja magoado ou que fique mal, o que nos aponta para uma crise vivida pela mulher que busca a sobrevivência de sua personalidade em meio às relações. (LIMA, 2004, p. 19)

De acordo com Marinho (2004, p. 75 - 76), Gilligan reorganiza os conteúdos e os níveis de desenvolvimento moral estabelecidos por Kohlberg e propõe uma nova estrutura para mulheres: o primeiro estágio se caracteriza como egoísta e individual, tipicamente infantil, voltado para si próprio. O segundo se apresenta como moral tradicional, que há tempos vem sendo seguido culturalmente. As moças aprendem a cuidar e se preocupar com o bem-estar dos outros, como: os irmãos mais novos, pais e avós. Constitui-se como errada a ideia de se voltar para os seus próprios interesses. Dessa forma, pode ocorrer a priorização dos interesses dos outros em vez dos seus e até mesmo fazer alguns sacrifícios em prol dos interesses dos outros. O terceiro é o estado pós-convencional, que compreende o processo de aprendizagem em equilibrar os dois tipos de interesse, e nenhum deve ser negligenciado, pois o fundamental é a relação com o outro: se o outro não estiver bem, compromete a relação, surgindo assim um dilema ético-moral.

Em seus estudos, Gilligan identificou duas orientações morais - uma pautada no cuidado e nos sacrifícios em prol do outro, geralmente presentes em mulheres, e outra fundamentada na justiça e nas regras mais rígidas e inflexíveis, majoritariamente presente em homens. A autora descreveu que essas duas orientações são construídas cultural e socialmente, que se iniciam na infância, quando o modo de tratamento com as crianças se diferencia de acordo com nosso sexo, e essa construção permanece na fase adulta, pois nossa sociedade é mergulhada na cultura do patriarcado.

Diante do exposto, para La Taille (2007), as teorias de Piaget e Kohlberg continuam sendo as mais fortes referências para os estudos sobre a moralidade humana no âmbito da Psicologia, apesar das turbulências que atingiram tanto a definição do objeto estudado quanto as variáveis psicológicas escolhi- 
das para explicar o desenvolvimento moral.

\section{CONSIDERAÇÕES FINAIS}

Piaget foi pioneiro em organizar o desenvolvimento moral sistematicamente, entendendo que a dimensão moral do desenvolvimento psicológico se refere ao respeito, por parte do indivíduo, pelas regras sociais e ao desenvolvimento do senso de justiça no sentido da reciprocidade e da igualdade. Nas palavras do próprio autor, "toda moral consiste num sistema de regras, sendo a essência da moralidade estudar o respeito que a pessoa vai adquirindo por essas regras". Para Piaget, a moral se desenvolve em três estágios: anomia, heteronomia e autonomia, e sua aspiração consistia em observar como ocorre a adaptação progressiva do sujeito às regras e à consciência que possui delas à medida que amadurece cronológica e cognitivamente.

Mesmo concordando com Piaget, Kholberg amplia e aprofunda os conceitos piagetianos. A metodologia utilizada para suas pesquisas envolve um instrumento criado por ele, com uma série de dilemas morais. Esses dilemas podem ser hipotéticos, quando mais abstratos e difíceis de ocorrerem, ou reais, quando encontrados mais facilmente no cotidiano da vida real.

Kholberg tenta descobrir a estrutura do juízo moral, ou seja, interessa-lhe saber como a pessoa estrutura o pensamento para chegar à resposta desses dilemas. A partir das respostas dos dilemas, ele concebe três níveis e seis estágios do desenvolvimento moral. Esses níveis representam três perspectivas diferentes que as pessoas podem adotar em relação às normas da sociedade. Já os estágios apresentam as razões que o sujeito utiliza para identificar uma ação como boa ou má.

Gilligan foi colega de Kholberg, trabalhando com os dilemas morais. Quando a pesquisadora publica seus primeiros estudos, sugere que as mulheres possuem uma moral distinta daquela proposta por Piaget e Kohlberg, ou seja, os raciocínios morais de mulheres e de homens são diferentes. Alguns anos depois, a autora conclui que a teoria de Kholberg não é adequada para avaliar as mulheres, visto que elas partem de uma estrutura de raciocínio moral que 
prioriza o cuidado e o bem-estar do outro, definido como a ética do cuidado. Os homens, segundo Gilligan, partem de uma estrutura de justiça. Nesse sentido, a autora afirma que as diferenças entre homens e mulheres encontradas por Kholberg se devem a um problema metodológico.

Pode-se constatar que a concepção tanto de Kohlberg como Gilligan apresentam aspectos relevantes e complementares, porque se entende que nem a justiça nem o cuidado podem ser desconsiderados nos estudos da moral. Talvez, seja importante haver uma reestruturação do pensamento moral e, para isso, a chave seria o equilíbrio dos dois pontos de vista para a compreensão do desenvolvimento moral.

À modo de conclusão, é importante sinalizar que esta pesquisa não teve com objeto de estudo a internalização dos valores morais, ou seja, "quando os valores deixam de ser leis impostas por agentes externos e convertem-se em diretrizes internas, legitimadas pela própria pessoa" (MÜLLER; ALENCAR, 2012, p. 456). Ou dito de outra forma, como as pessoas internalizam os valores morais, visto que a abordagem adotada se contrapõe a uma lógica de internalização passiva das normas sociais externas.

No entanto, não se pode deixar de mencionar que, apesar de a perspectiva cognitivo-desenvolvimental centrar sua atenção no componente cognitivo da moralidade, não nega a importância da socialização. Para Piaget, a criança constrói a lógica por meio das interações com outros. Portanto, a escola pode contribuir para o desenvolvimento da moral, criando contextos que privilegiem o diálogo, possibilidades de agir com autonomia, de cuidado mútuo, de reflexão às regras e aos dilemas morais. Enfim, contextos democráticos, em que os meninos e as meninas possam questionar, duvidar e apresentar novos pontos de vistas. Essas questões merecem ser enfocados em futuras pesquisas.

\section{REFERÊNCIAS}

BATAGLIA, Patrícia Unger Raphael; MORAIS, Alessandra de; LEPRE, Rita Melissa. A teoria de Kohlberg sobre o desenvolvimento do raciocínio moral e os instrumentos de avaliação de juízo e competência moral em uso no Brasil. Estud. psicol. (Natal), 
Natal, v. 15, n. 1, p. 25-32, Apr. 2010. Disponível em: https://www.scielo.br/scielo.php?pi$\underline{d=S 1413-294 X 2010000100004 \& s c r i p t=s c i \_a b s t r a c t \& t I n g=p t}$ Acesso em 20 de junho de 2020.

COIMBRA, J. L. (1990). Desenvolvimento interpessoal e moral. In B. P. Campos (Coord.), Psicologia do Desenvolvimento e Educação de Jovens, Vol. II (pp.18-29). Porto: Universidade Aberta.

DELVAL, J.; ENESCO, I. MORAL, DESARROLLO Y EDUCACIÓN. MADRID: ANAYA-ALAUDA, 1994.

FINI, Lucila DiehI Tolaine. Desenvolvimento Moral: De Piaget a Kohlberg. Perspectiva, Florianópolis, v. 9, n. 16, p. 58-78, jan. 1991. Disponível em: https://periodicos.ufsc.br/index.php/perspectiva/article/view/9127. Acesso em: 03 maio 2020.

KADOOKA, Aline; LEPRE, Rita Melissa; A EVANGELISTA, Vitor de Morais. Considerações sobre a Educação Moral de Kohlberg. Colloquium Humanarum, [s.l.], v. 12, n. , p. 16071614, 20 out. 2015. Associação Prudentina de Educação e Cultura (APEC). http://dx.doi. org/10.5747/ch.2015.v12.nesp.000788

LA TAILLE, Yves de. Moral e ética: dimensões intelectuais e afetivas. Artmed Editora, 2007.

LEPRE, Rita Melissa; MARTINS, Raul Aragão. Raciocínio moral e uso abusivo de bebidas alcoólicas por adolescentes. Paideia (Ribeirão Preto), [s.I.], v. 19, n. 42, p. 39-45, abr. 2009. FapUNIFESP (SciELO). http://dx.doi.org/10.1590/s0103-863×2009000100006.

LIMA, Vanessa Aparecida Alves de. De Piaget a Gilligan: retrospectiva do desenvolvimento moral em psicologia um caminho para o estudo das virtudes. : retrospectiva do desenvolvimento moral em psicologia um caminho para o estudo das virtudes. Psicologia: Ciência e Profissão, [s.I.], v. 24, n. 3, p. 12-23, set. 2004. FapUNIFESP (SciELO). http://dx.doi.org/10.1590/s1414-98932004000300003.

MACEDO, Alex Araújo. MORALIDADE NA ADOLESCÊNCIA EM SITUAÇÃO ESCOLAR: desenvolvimento e julgamento moral. 2015. 164 f. Dissertação (Mestrado) - Curso de Educação, Universidade Federal do Triangulo Mineiro, Uberaba, 2014. Cap. 1. Disponível em http://bdtd.uftm.edu.br/bitstream/tede/252/5/Dissert\%20Alex\%20A\%20Macedo.pdf. Acesso em: 06 maio 2020.

MARINHO, Manuela. Olhares femininos sobre a ética: Carol Gilligan e Nel Noddings. Intervenção Social, Lisboa, v. 29, p. 71-82, maio 2004. Semestral. Disponível em: http:// revistas.lis.ulusiada.pt/index.php/is/issue/view/73. Acesso em: 05 ago. 2020

PIAGET, J. Le jugement moral chez l'enfant. Paris: PUF, 1992. (Originalmente publicado 
em 1932)

PIAGET, Jean. O Juízo Moral na Criança. 4. ed. São Paulo: Summus, 1994

QUEIROZ, Kelly Jessie Marques; DE LIMA, Vanessa Aparecida Alves. Método Clínico piagetiano nos estudos sobre Psicologia Moral: o uso de dilemas. Schème: Revista Eletrônica de Psicologia e Epistemologia Genéticas, v. 3, n. 5, 2010

RAMOZZI-CHIAROTTINO, Z. Organismo, lógica e sociedade no modelo piagetiano do conhecimento. In: FREITAG, B. (Org.). Piaget: 100 anos. São Paulo: Cortez, 1997

SILVA, Matheus Estevão Ferreira da. Carol Gilligan e a Ética do Cuidado na produção de pesquisa em Psicologia do Desenvolvimento Moral de três programas de Pósgraduação Stricto Sensu (2008-2019). Schème: Revista Eletrônica de Psicologia e Epistemologia Genéticas, [S.L.], v. 12, n. 1, p. 166-204, 6 ago. 2020. Faculdade de Filosofia e Ciências. http://dx.doi.org/10.36311/1984-1655.2020.v12n1.p167-205.

SILVA, Gilberto Ribeiro e. O desenvolvimento da moralidade em Piaget e Kolberg. Paradigmas: Filosofia, Realidade e Artes, Santos, v. 13, n. 3, p. 6-6, abr. 2003. Bimestral. Disponível em: www.paradigmas.com.br . Acesso em: 05 maio 2020

TOLDY, Teresa Maria Leal de Assunção Martinho. Da Ética do Cuidar ao Universalismo Interativo. Fragmentos de Cultura, Goiânia, v. 25, n. 4, p. 585-595, out./dez. 2015.

VALE, Maria do Carmo. O Desenvolvimento Moral da Criança. Revista Portuguesa de Pediatria (antiga Acta Pediátrica Portuguesa): Ponto de Vista, Lisboa, v. 33, n. 5, p. 301-304, 19 set. 2014. Disponível em: https://pjp.spp.pt//article/view/5198. Acesso em: 06 maio 2020.

VALENTE, M. O. A Educação para os Valores. in E. L. Pires, O Ensino Básico em Portugal. Rio Tinto: ASA. 2002 